O. В. Попик,

к.е.н., м.н.с., Інститут проблем ринку та економіко-екологічних досліджень НАН Украӥни ORCID ID: 0000-0001-9170-2312

H.I. Хумарова,

д.е.н., с. н. с., Інститут проблем ринку та економіко-екологічних досліджень НАН Украйни ORCID ID: 0000-0001-5255-8004

DOI: $10.32702 / 2306-6806.2020 .4 .25$

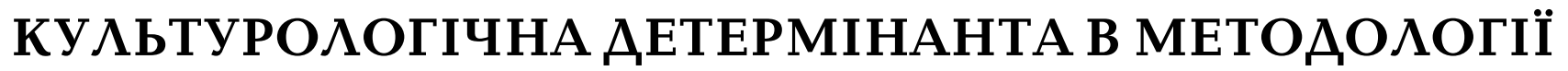 ВИЗНАЧЕННЯ РІВНЯ ІНКЛЮЗИВНОСТІ
}

O. Popyk,

PhD in Economics, Institute of Market Problems and Economic \& Ecological Researches of NAS of Ukraine

N. Khumarova,

Doctor of Economic Sciences, Institute of Market Problems and Economic \& Ecological Researches of NAS of Ukraine

\section{CULTURAL DETERMINANT IN METHODOLOGY OF THE INCLUSIVITY LEVEL MEASUREMENT}

\begin{abstract}
У представленій роботі наведено критичний аналіз методологічних засад та методичних підходів до визначення рівня інклюзивності. Розглянуто основні індикатори, що оцінюються під час розрахунку показника індексу інкАюзивного розвитку (IIP). Визначено певні недоліки та позицї̈ що потребують вдосконалення в існуючій методологічній системі. На основі глибинного аналізу вПливу культурологічних факторів на рівень соціально-економічного розвитку обгрунтовано доцільність імплементації сукупності відповідних індикаторів під час розрахунку характеристики інкАюзивності. Запропоновано деякі $з$ можАивих показників, що характеризують рівень впливу культурологічної,детермінанти на критерії інклюзивності. Визначено місце культурного капіталу та його економічну сутність у системі створення суспільного блага. Окреслено перспективи подальшого наукового пошукУв Сфері Удосконалення алгоритму обчислення індексу інкАюзивного розвитку.
\end{abstract}

The paper presents a critical analysis of methodological foundations and methodological approaches to determining the level of inclusivity. The main indicators, which are evaluated in the inclusive development index (IIR), are considered. Certain shortcomings and positions that need improvement in the existing methodological system are also considered. Based on the in-depth analysis of the influence of cultural factors on the level of socio-economic development, the feasibility of implementing a set of relevant indicators in calculating the characteristics of inclusivity is substantiated. Some of the possible indicators characterizing the level of influence of the cultural determinant on the criteria of inclusivity are proposed. The place of cultural capital and its economic essence in the system of creation of public goods is determined. The study identifies the influence of cultural background attribute on the development of socio-economic formations, and introduces the notion of cultural inclusivity as a cumulative category that include the potential for accessibility (including infrastructure) of cultural capital objects. Among the drowsy indicators that may be further taken into account in the process of calculating the index of inclusive development are the modified cultural heritage index, the coefficient of localization of cultural heritage objects and the gross domestic cultural product. The proposed indicators can be seen as a tool for explaining the nature of economic behavior through a set of external factors influencing the decision-making process and rooted in patterns shaped by the cultural past. Proposals for the inclusion of additional indicators in the algorithm for calculating IID solves the complex task of measuring the much undervalued potential of cultural capital, as a category of intangible economy with additional value. The prospects of further scientific research in the field of improving the algorithm for calculating the index of inclusive development are outlined.

Ключові слова: інклюзивність, методика визначення, культура, культурологічні засади, иінність, культурний капітал.

Key words: inclusivity, definition metbodology, culture, cultural foundations, value, cultural capital.

\section{ПОСТАНОВКА ПРОБЛЕМИ}

Історичний контекст теперішнього етапу суспільного розвитку концептуалізує та проголошує відкритість (доступність), рівність можливостей однією з фундамен- тальних домінант як особливу цінність не тільки в ідеалізованому гуманістичному вимірі романтизму минулого століття, а й елементом економічного прогресу та технологічного розвитку. Характеристика інклюзив- 
ності, створюючи додаткову економічну сутність, виходить за межі безумовно існуючої атрибутивності суспільного буття та постає певною одиницею, що має бути емпірично розрахованою та відповідно врахованою під час формування певних стратегічних орієнтирів і тактичних управлінських рішень.

За таких обставин існуючі методологічні підходи щодо виміру рівня соціально економічного розвитку чи благополуччя, в певному часово-просторову вимірі, якот: ВВП чи IP $\Lambda$ П втрачають свою об'єктивність через недостатнє врахування параметрів інклюзивності. Як відповідь на виникаючі виклики постає поява у 2017 р. на Всесвітньому Економічному Форумі у Аавосі індексу інклюзивного розвитку (IIP) та його визнання деякими провідними міжна родними інституціями, як об'єктивного інструменту обчислення не тільки і не стільки рівня розвитку економічних систем, а й рівня доступності сукупних створених благ для всіх верств населення, рівня залученості спільнот до загального процесу виробництва, у найбільш широкому дискурсивному сенсі.

Втім, інклюзивність постає настільки багатовимірним та комплексним поняттям, що притаманний більшості емпіричних підходів редукціонізм постає неспроможним виявити глибині ціннісні установки, що закладені в основі цієї дефініції. Витоки інклюзивності, як суспільно-економічного феномену, потрібно шукати в іншій площині комунікативної дійсності, на перетині систем господарювання та соціальних конструктів, як певний прояв конфлікту між природнім та штучним, як індикатор рівня розвитку культури. Саме в цьому аспекті вбачається простір для подальшого наукового пошуку.

\section{АНАЛІЗ ОСТАННІХ ДОСЛІДЖЕНЬ І ПУБЛІКАЦІЙ}

Питання методологічного забезпечення оцінки рівня соціально-економічного розвитку загалом та особливо через IIP, розглядаються в працях багатьох вітчизняних та зарубіжних науковців. Зокрема у дослідженні Ємельяненко М.М. та інших [1] проведено аналіз рівня інклюзивного розвитку в Україні із використанням методичних підходів ООН, МВФ та ОЕСР. Автори доходять висновку, що для досягнення стійкого інклюзивного розвитку необхідним є адоптація досвіду більшості розвинених країн, а саме перехід від окремих поодиноких заходів до вироблення комплексної стратегії соціально-економічного зростання. Щодо можливих ризиків і перспектив України на засадах інклюзивного розвитку розмірковує Прогнімак О.А. [2], справедливо зазначаючи, що у більшості стратегічних документів поняття інклюзивності, не зважаючи на його вживаність, виконує суто "декоративну" функцію, без розкриття змістовної сутності, попри наявність багатьох інструментів щодо створення відповідного правового поля Аля інклюзивного зростання.

Більш глибші методологічні дослідження розрахунку рівня інклюзивності в українських реаліях представлені у роботах Уніят А.В. [3], Зубчик О.А. [4] та Власенко Ю.Г. [5]. Зокрема посилаючись на методологічні підходи МВФ, автори розраховують IIP через часткові показники, такі як індекс інклюзивного зростання, індекс поглиблення бідності, індекс недотримання ВВП через безробіття та інші, що згруповано характеризують такі категорії як зростання та розвиток, інклюзивність та розподіл капіталу.

Цікавими також, з позиції подальшої імплементації, є дослідження Joyeeta Gupta [6], Kees van Paridon [7] та інших, у яких розглядається питання узгодження цілей сталого розвитку в тріаді соціальне-економічне-екологічне та інклюзивного розвитку в контексті розбудови нового, відкритого суспільства. Вагомий методологічний та методичний інструментарій із досить грунтовним математичним апаратом представлений у працях Mathias Hofmann [8] та Justin Yifu Lin [9]. Аослідники наголошують на позиції, що при використанні опитування у якості Ажерела інформації щодо інклюзивності, повинні бути застосовані механізми перевірки репрезентативності та релевантності отриманих результатів.

Попри вагомий науково-теоретичний базис та метоАичне забезпечення розрахунку IIP, визначення інклюзивності як атрибуту соціально-економічного розвитку $€$ не в повній мірі обгрунтованим, наповненим змістом, та відповідно потребує подальшого дослідження.

\section{META I ЗАВДАННЯ СТАТТІ}

Метою статті є розгляд та критичний аналіз основних методологічних підходів і методичних засад до визначення рівня інклюзивності. Основним завданням є пошук місця культури у формуванні характеристики інклюзивності та перспектив впровадження певних інструментів обчислення впливу культурологічної детермінанти на соціально-економічні показники в контексті інклюзивного розвитку.

\section{ВИКЛАД ОСНОВНОГО МАТЕРІАЛУ}

Інклюзивність як комплексне структурне явище інтегрує у собі спектр певним чином декомпонованих категорій. Серед основних позицій, що оцінюються постають здебільшого параметри включенності, залученості громадян не тільки у процес створення сукупного блага, а й процес споживання. Тобто у найбільш загальному наближенні економічний підхід визначає інклюзивність як характеристику рівня доступності соціальних послуг та економічних можливостей. У такому сенсі явище інклюзивності корелює із рівнем добробуту та фактично є тотожнім поняттю якості життя.

У більшості праць [1-3; 5; 7] розглядаючи явище інклюзивності акцент зміщується на суто потенційному, прогностичному вимірі. У центрі питання завжди посідає можливість оцінки ефекту "зростання", тобто те, що можливо мати при заданих умовах. За такого підходу темпоральність досліджень завжди знаходиться у випереджуючій стадії вимірюючи поступ. Попри вагому значимість подібних оцінок більш релевантними вбачаються параметри, що віддзеркалюють поточні кондиції, фактичну картину без прикрас та гіпотетичних здогадок, заснованих на експертних оцінках.

За методологією МВФ основними індикаторами, що характеризують інклюзивність у складі IIP є: медіанний рівень доходу, рівень бідності та коефіцієнт Ажинні (за доходами і за розподілом багатства). Зазначені показники відображають здебільшого ступінь нерівності в суспільстві [4], тобто соціальну стратифікаційну розшарованість. Проте виникає дещо риторичне питання який саме з перерахованих індикаторів віддзеркалює характеристику інклюзивності, та чи в повній мірі? Адже не тільки семантично, а й сутнісно глибинно купівельна спроможність, як певна похідна середнього рівню доходів, не є безсуперечним фактором інклюзії, враховуючи те, що можливість придбати щось не визначає наявність саме визначеного об'єкту бажання. Більш того, у цьому випадку який критерій може визначити, що саме постане об'єктом бажання та чинником вибору, як соціально-економічного явища, адже характеристика доступності блага в певній мірі є наслідком інтеракції між суб'єктом (із його сукупністю ментальних патернів та установок) та об'єктом (продуктом діючої господарської системи із певним рівнем атракції).

Саме в цьому аспекті вбачається істотна методологічна недосконалість та обмеженість існуючих підходів до визначення рівня інклюзивності, що полягає у:

- досить суттєвій прив'язці до економічних категорій, зокрема ВВП, при розрахунку та обчисленні індикаторів інклюзивності;

- відсутності об'єктивного виміру оцінки респондентів щодо рівня інклюзивності та відповідно кількісноякісного перетворення таких розрахунків;

- недостатнє врахування факторів і чинників що визначають поведінкові характеристики особистості, як головного агента та реципієнта благ інклюзії. 
Виходячи з вищенаведеного поняття інклюзивності, $€$ значно ширшим ніж характеристики, що його нині визначають. На нашу думку, інклюзивність необхідно розглядати як додаткову сутність, що визначає вільний вибір місця та часу для самореалізації і втілення власних бажань та можливостей [10]. Глибинні сутнісні корені інклюзивності потрібно шукати у факторах, що визначають поведінкові мотиви, зокрема й культуру, як соціально-економічний феномен, що одночасно є продуктом суспільного творення та фактором оточуючої дійсності, спроможним через інструменти культивування чи табуювання формувати поведінкові патерни.

$\Lambda$ оуренс Харісон починає свою працю [11] виразом "культура має значення", а потім послідовно та методично обгрунтовує свою тезу, наводячи безліч прикладів впливу культурологічних факторів на рівень добробуту. Наявність культурного капіталу (за П. Бурдьє), семантично проголошує певну безумовну економічну цінність та таким чином апостеріорно визначає важливість його врахування. Водночас слід розуміти, що суто арифметичне обчислення фізичної наявності наприклад закладів культури чи бібліотек, інформація про які міститься у більшості статистичних довідниках, ще не може вважатися характеристикою інклюзивності, проте в певній опосередкованій мірі воно є відображенням поняття доступності, в цьому випадку паперових носіїв знань, та може бути враховане як елемент об'єктивованого культурного капіталу.

Таким чином, постає очевидна необхідність доповнення існуючого індикатора інклюзивності у складі показника IIP певними уточнюючими параметрами та критеріальними засадами, що відображають вплив культури на рівень добробуту, на рівень розвитку та загалом формують певні поведінкові сценарії.

Вагомим методологічним доповненням до вже існуючого набору критеріїв можна вважати запропоновані Поливач К.А. [12] модифікований показник культурної спадщини $(W)$, та коефіцієнт локалізації об'єктів культурної спадщини $\left(K_{\text {док }}\right)$, що розраховується за формулою 1 та 2 відповідно.

$$
W=\frac{V}{\sqrt{(S \cdot P)}} \cdot \ln (S \cdot P)
$$

де $V$ - абсолютний показник кількості об'єктів;

$S$ - площа досліджуваної території;

$P$ - кількість населення території.

$$
K_{\text {лок }}=C_{\mathrm{rc}} / C_{S}
$$

де $C_{к c}$ - частка території за кількістю об'єктів культурної спадщини;

$C_{s}$ - частка території за площею.

Зазначені індикатори, хоча і в дещо спрощеній формі, проте відображають характеристику доступності об'єктів культурної спадщини у просторовому вимірі, розкриваючи саме аспект можливості залучення населення, та, як наслідок, у ретроспективному зрізі надають можливість оцінити вплив наявності зазначених об'єктів на рівень формування певних культурологічних засад у суспільному локусі зокрема через інклюзію.

У методології UNESCO [13] запропонований підхід щодо виміру впливу культури на рівень економічного розвитку, а саме через показник валового внутрішнього культурного продукту (CGDP), як складової ВВП, що розраховується за формулою 3.

$$
C G D P=\frac{\sum_{1}^{n}(G P V-I C)}{G D P}
$$

де $G P V$ - показник обсягу виробництва в сфері культури та дозвілля, що розраховується як сума прибутків від продажів, руху власних активів та виробничих запасів продукції (товарів та послуг);
$I C$ - показник середнього рівня споживання товарів та/або послуг;

GDP - показник ВВП.

В якості допоміжних індикаторів оцінки впливу рівня розвитку культури на економічні параметри пропонується також оцінювати рівень зайнятості населення в сфері культури та дозвілля, рівень освіти фахівців, що залучені у створення культурних продуктів та інші.

Інтеграція запропонованих показників в частковий індикатор інклюзивності у складі IIP можлива за допомогою математичного перетворення, зокрема правила усереднення "mini-max" та регресійного аналізу [9].

Основними перевагами доповнення методологічного апарату визначення рівня інклюзивності зазначеними параметрами можна вважати:

- появу об'єктивної можливості оцінення впливу етно-культурного контексту через індикатори наявності та доступності елементів культурної цінності (образних, просторових та ментальних);

- врахування факторів емоційного контексту щодо формування вибору та мотивів суб'єктів споживання (інтерсуб'єктивний вимір інклюзивності).

У загальному аспекті з'являється можливість більш повного та об'єктивного аналізу кореляційної залежності між рівнем розвитку економічних систем та культурологічним фоном. Запропоновані показники можуть розглядатися як інструмент пояснення природи економічної поведінки через сукупність певних екстернальних чинників, що впливають на процес прийняття рішень, та укорінені в площині, сформованих культурологічним минулим, шаблонів.

Визнаючи безумовність впливу атрибуту культурного фону на розвиток соціально-економічних формації постає очевидним уведення поняття інклюзивності культури, як кумулятивної категорії, що абсорбує потенціал доступності (зокрема й інфраструктурної) об'єктів культурного капіталу. Інклюзивність культури може бути ідентифікована зокрема через такі показники, як рівень медійної грамотності, культурної обізнаності, сталості етнокультурних регіональних традицій та інші.

Розширення параметричного набору детектованих показників у складі IIP, зокрема й через врахування індикаторів інклюзивності культури, дозволяє вивести його на дещо інший рівень та застосовувати отримані результати у контексті стратегічної оцінки і формування цілей сталого інклюзивного розвитку. Зокрема в тріаді соціальне-економічне-екологічне інклюзивність займає місце на перетині цих категорій, через забезпечення доступності і рівності прав для всіх членів суспільства в кожній із позицій. 3a Joyeeta Gupta [6] зелене зростання та інклюзивне зростання - це дві найбільше домінуючі дуальності, що мають неоліберальне коріння, але набувають додаткового виміру - збереження довкілля, чи невпинне економічне зростанням та подолання бідності. Завжди існує деяка контраверсійність цілепокладання у виборі пріоритетів, та, як наслідок, завжди присутній певний утиск (соціальний, екологічний чи економічний), зокрема й в контексті інклюзивності, що є похідною багатьох умовних.

\section{ВИСНОВКИ}

Наявність значного масиву теоретичних доробок визначає апріорну складність ідентифікації найбільш повного, в змістовному сенсі, та зручному для емпіричних розрахунків критерію під час оцінки рівня інклюзивності. Втім відмова від холістичного підходу в цьому випадку є вимушеним кроком для отримання найбільш релевантних результатів, що відображають фактичний рівень інклюзивності, через врахування широкого набору варіативних характеристик.

Культурологічна детермінанта при визначенні IIP обумовлює багатоманітність факторів, що зумовлюють 
інклюзивний розвиток. Пропозиції щодо включення додаткових індикаторів в алгоритм обчислення IIP вирішує комплекс завдання щодо вимірювання значно недооціненого раніше потенціалу культурного капіталу, як категорії нематеріальної економіки що володіє додатковою цінністю.

Перспективою подальших досліджень є вдосконалення методичних підходів до оцінки рівня інклюзивності та законодавчого визначення статусу цієї дефініції.

\section{\ітература:}

1. Емельяненко М.М., Петюх В.М., Азензелюк К.В. Інтегральна оцінка інклюзивного розвитку в Україні на національному та місцевому рівнях. Економіка та держава. 2019. № 6. С. 4-10

2. Прогнімак О.А. Інклюзивний розвиток України: перешкоди vs перспективи. Економічний вісник Аонбасу. 2018. № 1 (51). С. 187-197.

3. Уніят А.В., Юзвін 3.І. Концепція інклюзивної економіки в контексті сучасного сталого розвитку країн. Ефективна економіка. 2019. № 2. URL: http://www.economy.nayka.com.ua/?op $=1 \& z=6905$ (дата звернення: 19.02.2020)

4. Зубчик О.А. Індекс інклюзивного розвитку як сучасний інструмент аналізу державної політики. Вчені записки Таврійського національного університету імені B.I. Вернадського. Серія: Аержавне управління. 2018. T. 29(68), № 1. C. 86-91.

5. Власенко Ю.Г. Міжнародні підходи до методики оцінки інклюзивності. Науковий вісник Ужгородського національного університету. Серія: Міжнародні економічні відносини та світове господарство. 2019. Вип. 24 (1). С. $70-74$.

6. Joyeeta Gupta, Courtney Vegelin, Sustainable development goals and inclusive development. Int. Environ Agreements. 2016. № 16. P. 433-448.

7. Kees van Paridon, Towards a more inclusive future: On the delicate balance between economic change and social stability in a time of globalisation. List Forum. 2018. № 44. P. 241-281.

8. Mathias Hofmann, Sander Munster,Jorg Rainer Noennig. A Theoretical Framework for the Evaluation of Massive Digital Participation Systems in Urban Planning. Journal of Geovisualization and Spatial Analysis. 2019. № 2020 . P. $1-12$.

9. Justin Yifu Lin, Celestin Monga, Samuel Standaert. The Inclusive Sustainable Transformation Index. Social Indicators Research. 2019. № 143. P. 47-80.

10. Попик О.В., Хумарова Н.I. "Простір свободи": Теоретичні підвалини інклюзивності урбанізованих територій. Вчені записки ТНУ імені В.І. Вернадського. Серія: Економіка і управління. 2019. № 6. С. 98-103.

11. Харисон $\Lambda$. Евреи, конфуцианцы и протестанты: культурный капитал и конец мультикультурализма. Москва: Мысль. 2019. 286 с.

12. UNESCO Culture for Development Indicators: Methodology Manual. 2014. 144 p.

13. Поливач К.А. Культурна спадщина та її вплив на розвиток регіонів України. К.: Інститут географії НАН України. 2012. 208 с.

\section{References:}

1. Yemelianenko, L. Petiukh, V. and Dzenzeliuk, K. (2019), "Integral assessment of inclusive development in Ukraine at national and local levels", Ekonomika ta derzhava, vol. 6, pp. 4-10.

2. Prohnimak, O. (2018), "Inclusive development of Ukraine: obstacles vs perspectives", Ekonomichnyj visnyk Donbasu, vol. 1 (51), pp. 187-197.

3. Uniyat, A. V. and Yuzvin, Z. I. (2019), "The concept of inclusive economy in the context of modern sustainable development of countries", Efektyvna ekonomika, [Online], vol. 2, available at: http://www.economy.nayka.com.ua/ ?op $=1 \& z=6905$ (Accessed 28 Feb 2020).

4. Zubchyk, O. (2018), "Index of inclusive development as a modern tool for analyzing public policy", Vcheni zapysky Tavrijs'koho natsional'noho universytetu imeni V.I. Vernads'koho. Seriia: Derzhavne upravlinnia, vol. 1, pp. 86-91.

5. Vlasenko, Y. (2019), "International approaches to the assessment method of inclusiviness", Naukovyj visnyk Uzhhorods'koho natsional'noho universytetu. Seriia: Mizhnarodni ekonomichni vidnosyny ta svitove hospodarstvo, vol. 24 (1), pp. 70-74.

6. Gupta, J. and Vegelin, C. (2016), "Sustainable development goals and inclusive development", Int. Environ Agreements, vol. 16, pp. 433-448.

7. Paridon, K. van (2018), "Towards a more inclusive future: On the delicate balance between economic change and social stability in a time of globalisation", List Forum, vol. 44, pp. $241-281$.

8. Hofmann, M. Munster, S. and Noennig, J. R. (2019), "A Theoretical Framework for the Evaluation of Massive Digital Participation Systems in Urban Planning", Journal of Geovisualization and Spatial Analysis, vol. 2020, pp. 1-12.

9. Lin, J. Y. Monga, C. and Standaert, S. (2019), "The Inclusive Sustainable Transformation Index", Social Indicators Research, vol. 143, pp. 47-80.

10. Popyk, O. and Khumarova, N. (2019), "Space of freedom": Theoretical bases of inclusion of urbanized areas", Vcheni zapysky TNU imeni V.I. Vernads'koho. Seriia: Ekonomika i upravlinnia, vol. 6, pp. 98-103.

11. Kharison, L. (2019), Evrei, konfuczianczy`i protestanty`: kul'turny“j kapital i konecz mul'tikul`turalizma [Jews, Confucians and Protestants: Cultural Capital and the End of Multiculturalism], My`sl', Moscow, Russia.

12. UNESCO (2014), Culture for Development Indicators: Methodology Manual.

13. Polyvach, K. (2012), Kul'turna spadschyna ta ii vplyv na rozvytok rehioniv Ukrainy [Cultural heritage and its influence on the development of regions of Ukraine], Instytut heohrafii NAN Ukrainy, Kyiv, Ukraine. Стаття надійшла до редакиї 10.03.2020 p.

\section{Електронне фахове видання}

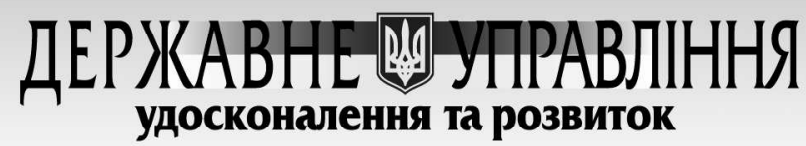

Виходить 12 разів на рік

включено до переліку наукових фахових видань України 3 ПИтань ДЕРЖАВНОГО УПРАВЛІННЯ

(Категорія «Б»)

Наказ Міністерства освіти і науки України від 28.12.2019 №1643

e-mail: economy_2008@ukr.net тел.: (044) 223-26-28 (044) 458-10-73 